\title{
Preparing the Self for Team Entry: How Relational Affirmation Improves Team Performance
}

\section{Citation}

Lee, Julia J., Francesca Gino, Daniel M. Cable, and Bradley Staats. "Preparing the Self for Team Entry: How Relational Affirmation Improves Team Performance." Harvard Business School Working Paper, No. 16-111, March 2016.

\section{Permanent link}

http://nrs.harvard.edu/urn-3:HUL.InstRepos:26211018

\section{Terms of Use}

This article was downloaded from Harvard University's DASH repository, and is made available under the terms and conditions applicable to Open Access Policy Articles, as set forth at http:// nrs.harvard.edu/urn-3:HUL.InstRepos:dash.current.terms-of-use\#OAP

\section{Share Your Story}

The Harvard community has made this article openly available.

Please share how this access benefits you. Submit a story.

Accessibility 


\section{Preparing the Self for Team Entry: How Relational Affirmation Improves Team Performance}

Julia J. Lee

Daniel M. Cable
Francesca Gino

Bradley R. Staats

Working Paper 16-111 


\title{
Preparing the Self for Team Entry: How Relational Affirmation Improves Team Performance
}

\author{
Julia J. Lee \\ University of Michigan \\ Daniel M. Cable \\ London Business School
}

\author{
Francesca Gino \\ Harvard Business School \\ Bradley R. Staats \\ University of North Carolina at Chapel Hill
}

Working Paper 16-111 
Preparing the Self for Team Entry:

\title{
How Relational Affirmation Improves Team Performance
}

\author{
Julia J. Lee \\ University of Michigan \\ jooalee@umich.edu \\ Francesca Gino \\ Harvard Business School \\ fgino@hbs.edu \\ Daniel M. Cable \\ London Business School \\ dcable@london.edu \\ Bradley R. Staats \\ University of North Carolina at Chapel Hill \\ bstaats@unc.edu
}

\section{Acknowledgments}

This research was supported by the Pershing Square Venture Fund for Research on the Foundation of Human Behavior, the Mind/Brain/Behavior Interfaculty Initiative at Harvard University, Harvard Business School, London Business School, and the University of North Carolina in Chapel Hill. We greatly appreciate the support provided by Pete Zimmerman, the Chair of the Senior Executive Fellows Program. We also thank Alex Hu, Jong Hyun Jang, Ashley Kirsner, Beckett Mullen, Nga Nguy, and Ceylan Oymak for their research assistance. For insightful feedback, we are grateful to Jane Dutton and seminar participants at the Ross School of Business, and Jeff Polzer. 


\begin{abstract}
Working in teams often leads to productivity loss because the need to feel accepted prevents individual members from making a unique contribution to the team in terms of the information or perspective they can offer. Drawing on self-affirmation theory, we propose that pre-team relational self-affirmation can prepare individuals to contribute to team creative performance more effectively. We theorize that relationally-affirming one's self-views increases general feelings of being socially valued by others, leading to better information exchange and creative performance. In a first study, we found that teams in which members affirmed their best selves prior to team formation (i.e., by soliciting and receiving narratives that highlight one's positive impact on close others) outperformed teams that did not do so on a creative problem-solving task. In the second experiment, conducted using virtual teams, we show that pre-team relational self-affirmation leads to heightened feelings of social worth, which in turn explains the effect of the treatment on the team's ability to exchange information.
\end{abstract}

Keywords: relational self-affirmation; team entry; team creative performance; information exchange; social worth. 


\section{Preparing the Self for Team Entry:}

\section{How Relational Affirmation Improves Team Performance}

Effective communication is a key feature of a team's capabilities (Eisenhardt and Martin, 2000; Gardner, Gino, and Staats, 2012). Unfortunately, as members are introduced to a team, one critical issue that may impede effective team communication is each member's need to feel accepted by the others (Wittenbaum and Stasser, 1996; Gruenfeld et al., 1996). The need to feel accepted can lead individual members to prioritize fitting in over contributing unique information and adding maximum value to the team. For example, teams are biased toward repeating previously-mentioned shared information, as opposed to sharing unique information, because repetition helps members appear "cognitively central and thus task competent” (Wittenbaum, Hubbell, and Zuckerman, 1999; p. 968). In addition, team members are more likely to share socially-endorsed information within the team if they believe the information to be useful to the team as compared to information that has not been socially-validated (Littlepage, Perdue, and Fuller, 2012). Thus, individual team members’ need for social acceptance may hinder the team's ability to share and integrate information in order to accomplish their task.

One remedy to this problem is for members to invest time after team formation, to highlight their differences in ideas, background and perspectives. As evidenced in a qualitative study of diverse teams by Ely and Thomas (2001), openly discussing the unique qualities of different team members and integrating diverse perspectives allowed individuals to feel valued and respected. The team members were able to apply their differences in knowledge, and the perspectives associated with their unique identities, to the task at hand, which enhanced the team's cross-cultural learning and performance. The self-verification literature offers a similar 
message about how individual members become more integrated into a team. The more that team members felt that others' appraisals were in line with their own personal self-views (Swann et al., 2004), the more that diverse teams achieved high levels of creative performance (Polzer, Milton, and Swann, 2002; Swann et al., 2003).

In this paper, we draw upon self-affirmation theory to add a different psychological process that can facilitate team member's identity negotiation as one prepares to work in a team. In particular, we explore the idea that actions immediately prior to joining a team may aid the team coordination process. Self-affirmation research, in which vulnerable individuals’ core values are affirmed, has been shown to reduce the threat to one's self-image by making people feel more secure in their self-worth (Sherman and Cohen, 2002). Conceptually, positioning a self-affirmation process before team formation can refocus individuals’ cognitive resources and, thus, increase their value to the team. We propose that using self-affirmation to strengthen team members’ core values (e.g., how they are making contributions to their personal network) - from sources external to the team and prior to the team's task - reduces individuals' concerns about social acceptance, resulting in better information exchange within the team.

Self-affirmation is an approach to remind people of their psychosocial resources (e.g., social network, core values, valuable traits) in order to demonstrate one’s adequacy (Cohen and Sherman, 2014). Most self-affirmation research focuses on one's own view of the self in order to motivate improved behavior (McQueen and Klein, 2006). Instead of focusing on one’s own recollections, in this paper, we introduce the construct of relational self-affirmation. Because team entry is inherently social, we focused on relational aspect of self-affirmation to highlight the team member's existing social network. Relational self-affirmation thus capitalizes on one’s pre-existing personal network of relationships (friends, family, and coworkers) who write 
narratives about times the individual made a distinct contribution (Roberts et al., 2005). Because these narratives come from different social sources prior to an individual's entry into a team, they allow her to draw from strengths that may not have occurred to her as core to her selfconcept, or that she might not have applied to the team context. Strengthened by a comprehensive set of self-defining moments, the focal individual is better prepared to bring unique value in a novel team setting without feeling threatened by social concerns. Our work thus demonstrates how a team can benefit from tapping into individual members’ personal, social resources in order to relationally-affirm individual members prior to team entry. Figure 1 depicts our proposed multi-level model.

Our research offers three key contributions to existing research.

First, we integrate the self-affirmation and intragroup processes literature, and propose that a specific type of self-affirmation can help team members to be in the psychological state that prepares them to contribute to the team task. We draw on Cooley’s description of the looking glass self (1902), in which reflected appraisals (i.e., how significant others see the self) are critical in affirming (Oyserman, Elmore, \& Smith, 2012), constructing and modifying one’s self-concept (e.g., Baumeister, 1982, 1986; Wicklund \& Gollwitzer, 1982). Much of such research on social construction of self has shown that people tend to incorporate what they believe others think of themselves (Shrauger \& Schoeneman, 1979). While the literature on selfaffirmation has focused on invoking the values that matter most to individuals, our research on relational self-affirmation demonstrates the value of social feedback by explicitly bringing in reflected appraisals to assist individuals to affirm their self-views.

Second, our study is the first to show how pre-team relational self-affirmation can lead to better team performance, such as increased idea generation and information integration. In 
addition to the practical importance of getting new teams up to speed quickly, our research how existing personal relationships can improve team members’ psychological and motivational states, a topic which has been largely ignored in the intergroup processes literature. As individuals situate their new team context as an outlet for making a positive impact on others, we theorize that individuals who are affirmed make better use of their creative resources. As a result, teams comprised of such individuals can enjoy important performance benefits. Thus, our work highlights the importance of relational self-affirmation when it temporally precedes working in a team setting.

Third, we contribute to the literature on intragroup processes by theorizing about the mechanism through which pre-team relational self-affirmation results in higher levels of team performance. This is important, as recognized by team scholars who have called for identifying the micro-level factors that improve a team's ability to solve problems creatively (Neuman and Wright, 1999; Taggar, 2002), as well as a team’s capability to effectively share unique information (Sohrab, Waller, and Kaplan, 2015). We provide novel evidence that pre-team relational self-affirmation reminds individuals of their social worth, namely a sense of being valued by others and a basic human motivation (McAdams \& de St. Aubin, 1992; Ryan \& Deci, 2000). As a result, it prepares them to bring their best to the team, and further facilitates the team’s ability to exchange information. We thus propose a multi-level model that links individual psychological states to team-level outcomes, responding to the call for tests of motivational mechanisms that drive team creative performance.

\section{THEORETICAL MODEL AND HYPOTHESES}

A team's ability to solve problems creatively may not be greater than the sum of its individual members' creative ideas. Most people believe they can contribute more creative ideas 
when they work in teams than when they work alone (Stroebe, Diehl, and Abakoumkin, 1992; Pauhus et al., 1993). Despite this prevalent belief that team interactions will stimulate creative thinking, research on brainstorming shows that pooling ideas from people working alone leads to more creative ideas than having the same people generate ideas in a team setting (Taylor, Berry, and Block, 1958; Lamm and Trommsdorff, 1973; Diehl and Stroebe, 1987; Mullen, Johnson, and Salas, 1991; Brown and Paulus, 2002). In this section, we first review research that points to team members’ concerns about social acceptance as a key reason for team productivity loss, and we identify feelings of social worth as a psychological mechanism that can override such concerns. We then establish a multi-level model of how pre-team relational self-affirmation at an individual level can increase one's feelings of social worth, thus improving team-level processes encompassing the team's strategy planning, information gathering and sharing, as well as creative performance outcomes.

\section{Relational Self-Affirmation and Feelings of Social Worth}

Starting a new job, transferring to a new department, or joining a new team can stir feelings of worry, anxiety, and stress (Katz, 1985). Just as organizational entry "thrust(s) one from a state of certainty to uncertainty; from knowing to not knowing; from the familiar to the unfamiliar” (Van Mannen, 1977; p. 16), joining a new team can similarly make individuals feel as if they are outsiders. As individuals are expected to connect with other team members and perform a collaborative task, it is natural to worry that others may not accept them and instead may judge them based on first impressions. Research has robustly and consistently found that teams perform more effectively when members’ appraisals of each other are in line with their own personal self-views (Swann et al., 2004; Polzer et al., 2002). Given that a team member’s anxiety over social acceptance is a key motivational factor that can dampen the team's ability to 
perform, it is important to examine the conditions that would make team members more likely and willing to contribute their unique knowledge and ideas. We thus propose an alternative approach to increasing the team's creative performance by easing members' anxiety over social acceptance before they even meet the other members.

Scholars of narrative psychology focus on how humans organize their experiences into self-narratives that consist of plots, characters, settings, and conflicts (Sarbin, 1986). Selfnarratives create, develop, and maintain the self-concept, which is a collection of selfrepresentations (Singer and Salovey, 1983; McAdams, 1996; Ibarra and Barbulescu, 2010), and ground one's memories in a meaningful context of personal history (McAdams, 1988). Such narratives, particularly those that convey core values representing oneself, can be reinforced and affirmed by reading stories from one's personal network that highlight instances of positive impact. Conceptually, the process of elaborating one’s self-narrative based on impact narratives can give individuals clarity over their self-concept - and offer new insights into their enduring strengths and social influence (Roberts et al., 2005). Rather than simply reflecting on their values and personal attributes, individuals can rely on the stories as remembered by close others through relational self-affirmation. Because such stories are often not explicitly shared, reading them can cause individuals to pause and reflect on their life experiences. More generally, this iterative process can produce strong emotional responses that induce changes in self-knowledge structures and contribute to positive identity construction (Roberts et al., 2005; Dutton, Roberts, and Bednar, 2010).

Drawing on this line of research, we argue that relational self-affirmation that highlights one's positive contribution to their social network will therefore increase their feelings of social worth. Psychologists have suggested that the desire to be valued and needed by others (i.e., the 
pursuit of social worth) is a basic human motivation (McAdams \& de St. Aubin, 1992; Ryan \& Deci, 2000). Experiencing social worth makes individuals feel that their actions matter in the life of other people (Elliott, Colangelo, \& Gelles, 2005; Rosenberg \& McCullough, 1981), which heightens their sense of belongingness (Baumeister \& Leary, 1995; Keyes, 1998). In the work context, scholars have proposed that employees interpret interpersonal cues from others as affirming or disaffirming of who they are as a person, which leads to one's sense of confirmed worth as a human being (Wrzsniewski, Dutton, \& Debebe, 2003). Thus, we posit that relational self-affirmation will increase one’s feelings of social worth.

Hypothesis 1. Relational self-affirmation increases one's feelings of social worth.

\section{Concern about Social Acceptance as a Barrier to Information Exchange and Creative Performance in Teams}

Team coordination involves the use of strategies and behavior patterns to integrate and align the actions, knowledge, and objectives of team members to attain common goals (e.g., Malone \& Crowston, 1994; Zalesny, Salas, \& Prince, 1995). As Taggar noted (2002), a team’s ability to effectively utilize the unique resources individuals bring to the team is critical for team creative performance, especially given the increasing use of teams to foster creativity (Mohrman, Cohen, \& Mohrman, 1995; Tesluk, Farr, \& Klein, 1997). Past research has treated the research on information exchange as a key process by which teams ensure that they function optimally while preventing the team's productivity loss (e.g., McGrath \& Argote, 2001; Tannenbaum, Beard, \& Salas, 1992). There is ample evidence pointing to the positive relationship between team's ability to exchange information and its performance (for a meta-analysis, see MesmerMagnus \& DeChurch, 2009); for instance, Stout et al. (1999) found that better coordination in teams led to greater information sharing, and higher performance on a simulation task. Similarly, 
open communication predicted better team performance (Barry \& Stewart, 1997; Hyatt \& Ruddy, 1997), and effective information sharing increased group performance through information-seeking behaviors of the team members (Durham et al., 2000).

Concerns about social acceptance also can undermine the team’s ability to effectively gather and integrate information from its members, in particular. For example, effective communication during a task could take the form of contributing unique, unshared information to the team (Stasser and Titus, 1985), and requesting information from others about missing information to facilitate the integration process (Edmondson, 1999). It has been well known that teams are more likely to rely upon shared information, as compared to unique information, and that this preference is sub-optimal for team performance. Wittenbaum, Hubbell, and Zuckerman (1999) tested the idea that this preference by teams for shared information stems from members' tendency to positively evaluate one another during their discussion of shared information and validate such information (the "mutual enhancement effect"). According to the "consensus implies correctness” heuristic (Chaiken and Stangor, 1987), members communicating shared information are viewed as competent and knowledgeable by other team members. Consistent with this perspective, individuals who rate high on social desirability are more likely to focus on discussing communal information than those who rate low on social desirability (Henningsen and Henningsen, 2004). Because members cannot readily validate unique information, the team remains uncertain about the information's value (Littlepage, Perdue, \& Fuller, 2012). Likewise, team members may not actively seek out information from others if they are worried about being rejected (Flynn and Lake, 2008).

A team’s inability to share and pool information from different members may lead to suboptimal outcomes in creative performance. Research on information integration has examined 
how teams distribute information that is known either by all members (i.e., communal information) or by a single member (i.e., unique information) (Stasser and Titus, 2003). Pooling information would lead the team to discover a so-called "hidden profile" and choose the best decision alternative; failing to do so would leave them with a suboptimal alternative. This research has reliably shown that teams rarely discover the hidden profile because they discuss proportionally more communal than unique information (Wittenbaum, Hollingshead, and Botero, 2004). Specifically, team members are more likely to mention, repeat (Larson, Foster-Fishman, and Keys, 1994), and rate communal information as more important, accurate, and relevant (Wittenbaum, Hubbell, and Zuckerman, 1999) than unique information.

Anxiety over social acceptance can be crippling for performance outcomes, because it makes team members less likely to take interpersonal risks, preventing a team from tapping into its members' full potential to integrate their unique perspectives. Concern about social belonging leads to the cognitive suppression of unique perspectives (Carver and Scheier, 1981; Sanna and Shotland, 1990), which could reduce members’ ability to contribute creative ideas to the team. In addition, individuals working in teams often experience discomfort and anxiety about being socially accepted by the team and so either conform to a team's shared knowledge (Gruenfeld et al., 1996) or avoid taking interpersonal risks, voicing new ideas and speaking up about potential mistakes (Edmondson, 1999). To the extent that individuals attempt to fit in in order to avoid social norm violations and ostracism, they may become increasingly reluctant to share unique knowledge that may be inconsistent with others’ contributions (Baron, Kerr, and Miller, 1992). In sum, individuals’ concern about social acceptance likely reduces their motivation to disclose unique data or information to the team, and actively tap into other members’ knowledge, and this could be costly to the team's creative performance. 


\section{Social Worth as a Psychological Mechanism for Pre-team Relational Self-Affirmation}

In the previous section, we have identified concerns for social acceptance to be a potential factor that could dampen the team's ability to exchange information and perform. As predicted in Hypothesis 1, explicitly affirming team members' unique positive attributes and perspectives by their personal network should make them feel socially valued. When individuals experience social worth, they feel needed, cared about, and valued by others - all feelings that signal the presence of an interpersonal bond or positive relationship (Bakan, 1966; Kaplan \& Kaplan, 2003; Wrzesniewski, Dutton, \& Debebe, 2003). In fact, Crocker, Niiya, and Mischkowski (2008) identified self-transcendence as a mechanism by which generalized valueaffirmation interventions (e.g., writing about and reflecting on important values) reduce one's defensiveness against threatening health information. They noted that prior research did not find reliable support for self-worth or positive affect as a mechanism explaining the effects of valueaffirmation on defensiveness. Instead, they demonstrated that value-affirmation induce positive other-directed feelings, because reflecting on important values enables individuals to transcend concerns about self-image or self-worth.

Similar to generalized value-affirmation, we propose that pre-team relational selfaffirmation amplifies feelings of social worth, thereby offsetting their concerns about social acceptance and reducing the threat to one’s self-image. Importantly, we predict that such relationally-affirmed self-views will carry over to a novel team context. This will allow team members to transcend their concerns about social acceptance as they enter into the team. Because individuals will be less anxious about fitting in with others, they may become emboldened to ask for information, or offer creative ideas and insights they may otherwise have felt too inhibited to share (Swann et al., 2004). We thus predict that increasing team members' feelings of social 
worth prior to team formation will enhance their willingness and likelihood to take more interpersonal risks (i.e., asking for others' information) and share unique perspectives when the team starts operating. The team's ability to integrate the unique information that each member brings to the table will in turn increase team’s creative performance.

Hypothesis 2. Pre-team relational self-affirmation increases team-level outcomes such as information exchange and creative performance in teams.

Hypothesis 3. The effect of pre-team relational self-affirmation on team-level outcomes is mediated by feelings of social worth.

\section{Overview of the Present Research}

We designed two randomized controlled studies of senior executives (Study 1) and virtual workers (Study 2) to observe how pre-team relational self-affirmation affects team process (i.e., information exchange) and outcome (i.e., team creative performance). As such, we attempted to maximize both internal and external validity. One key feature of both samples is that these teams were self-managed and comprised of individuals who were not familiar with each other before starting the tasks. To maximize team diversity, Study 1 participants were assigned into teams such that no two members were from the same organization. Study 2 participants were recruited from a large online population in Amazon Mechanical Turk and participated in a team task anonymously and virtually. This feature allowed us to examine how unfamiliar team members interact and communicate with each other, and ruled out members' preexisting interpersonal knowledge as a predictor of team outcomes. The only difference between treatment and control teams is whether the team members' pre-team relational selfaffirmation occurred before or after the team task. 


\section{STUDY 1}

This study examined the team performance of a sample of senior leaders who participated in a four-week leadership development program at a top government school in the United States. In the treatment group, senior leaders received the relational self-affirmation treatment before participating in a crisis simulation related to public health, while those in the control groups received the relational self-affirmation treatment after the conclusion of the study. In Study 1, teams participated in a crisis simulation, which ended with a team presentation evaluated by expert panels. Thus, Study 1 tests whether pre-team relational self-affirmation at an individual level enhances expert-rated team outcomes in creative performance.

\section{Sample and Procedures}

In this study, we worked with a unique sample of leaders from the executive education program who were career civil servants (a majority work for the U.S. government) or current or former military officers. Many of the participants were candidates for promotion to senior executive or general officer ranks. This program is offered three times a year, in February, April, and October, and approximately 70 fellows are admitted to each program. Each program is 4 weeks long. A total of 246 participants participated in this program $\left(M_{\text {age }}=48.47, S D_{\text {age }}=7.13\right.$; 73\% male). We collected data from four sessions: October-November $2013(N=31)$, FebruaryMarch $2014(N=70)$, April-May $2014(N=80)$, and October-November $2014(N=65)$.

Pre-arrival assignment. A few weeks before the participants' arrival on campus, the program staff emailed all participants and asked them to complete a three-step pre-arrival assignment. We followed the procedures outlined in the Reflected Best Self Exercise (Roberts et al., 2005). First, all participants had to submit their own self-assessment in which they described three narratives from their lives when they were at their best. Second, participants were asked to 
identify a minimum of five to ten people in their personal social network who knew them well and could describe narratives when participants were at their best. Participants were encouraged to include a mix of contacts, including friends, mentors, family members, customers, and colleagues. Third, these social network members were contacted and invited to write up to three detailed narratives describing occasions when the participant was at his or her best. A third-party organization compiled the stories and created a report for each participant made up of all the narratives written by their social network.

Group assignment and experimental manipulation. In order to manipulate pre-team relational self-affirmation and observe its effects on team creative performance, the program director first assigned participants to teams consisting of five or six fellows. For the intervention, the program director also randomly assigned the teams to either the treatment or control condition. We had a total of 42 groups (22 treatment groups and 20 control groups) across four programs over two years. ${ }^{1}$ All participants sat together as a team as assigned by the program director on the third day of Week 1, at which time each individual learned about their team assignment and received a package. Following Roberts et al. (2005), individuals in teams assigned to the treatment condition received a package that included the impact narratives, as well as worksheets to facilitate their reflection on the narratives by writing a self-portrait incorporating new insights from the impact narratives. The teams in the control condition did not receive the impact narratives but instead received a worksheet to prepare for a team discussion to take place later in one of their classes. All teams were given an hour to complete their respective tasks. Participants were told not to discuss with others what they had received (either within the

\footnotetext{
${ }^{1}$ The breakdown of each program is as follows: 6 teams (3 treated) in October-November 2013, 12 teams (6 treated) in February-March 2014, 13 teams (7 treated) in April-May 2014, and 11 teams (6 treated) in October-November 2014.
} 
team or outside the team), both to give the treatment groups the opportunity to privately reflect on what they received, and also to minimize the suspicion of the control groups that they had received different materials from the treatment groups.

Crisis simulation as a team task. Ten days after the manipulation took place, the program launched a crisis-simulation exercise for all teams. The teams played the role of an Emergency Watch Team that was working in the local state government to monitor developments following the report of a dangerous coronavirus detected in their state (see Appendix A). Participants received information from various sources (e.g., tweets, news stories, etc.) for seven days leading up to the briefing day, which they had to react to and make decisions about. On the day of the briefing, each team made a 20-minute presentation to a panel of external experts consisting of individuals from the U.S. government and faculty members. The expert panels (a total of 16 judges), which were blind to the experimental conditions, spent five minutes giving each team feedback on its performance and completed an evaluation form with our dependent measures. ${ }^{2}$ Thus, as an objective measure of the team's creative performance, we examined experts’ ratings of teams’ analyses and responses to the hypothetical crisis. After all data collection from the crisis simulation was concluded, we debriefed all teams in a separate session and distributed the pre-team relational self-affirmation to those in the control condition.

\section{Measures}

Team creative performance. Out of four programs, the first two used a 5-point scale (from 1 = “needs improvement” to 5 = “excellent”), and the last two used a 7-point scale (from

\footnotetext{
2 Each team presented to a panel of "top state officials and experts" consisting of faculty members with various expertise, as well as external experts from the U.S. government, such as the current director of the Massachusetts Emergency Management Agency / Undersecretary for Homeland Security and Emergency Management in the Executive Office of Public Safety, a former U.S. Customs and Border Protection commissioner, and the director of the Bureau of Infectious Disease at the Massachusetts Department of Public Health.
} 
1 = “needs improvement” to 7 = “excellent”). Thus, we standardized the scales within programs using z scores. Because of limited number of available experts for the different sessions, different teams of expert panels evaluated different teams. Each team of three to four expert panels evaluated up to six teams’ presentations, based on the following criteria: effective communication (whether the team members communicated their recommendation effectively), creativity (whether their recommendations were creative and innovative), clarity (whether their recommendations were clear and succinct), feasibility (whether the policy recommendations were realistic and feasible), team cohesiveness (whether the team members showed an ability to relate to each other), and overall value of the content to the decision maker. Given that all of these items loaded on a single factor (eigenvalue $=4.91$, variance explained $=81.82 \%$ ) and that the experts’ ratings demonstrated acceptable interrater reliability (ICC1 = 42.5, ICC2 = 68.92), we created a summary variable by averaging the items to indicate overall team creative performance $(\alpha=0.95)$.

\section{Results}

Data analysis strategy. We controlled for theoretically-relevant covariates that may have influenced team-level outcomes. First, we controlled for team-specific characteristics, such as mean age and gender composition (ratio of females to males) following the literature on team diversity and collective intelligence (Polzer, Milton, and Swann, 2002; Woolley et al., 2010). In addition, we controlled for team size, drawing on previous work showing that smaller teams are more likely to share information and make effective decisions than larger teams (Cruz, Boster, and Rodríguez, 1997). Finally, we added dummy-coded variables indicating the group of expert panels who evaluated each of the teams, because a total of nine different groups of expert panels evaluated the teams over the duration of this study. This control variable also allowed us to 
control for the any factors that could have changed over time (such as course schedule and curriculum). For example, the fellows in the October-November 2014 program had more experience working as a team as the result of a curriculum change, which could have increased their overall team performance as compared with previous programs. We report summary statistics and zero-order correlations among the key variables in Table 1.

***** Insert Table 1 about here $* * * * *$

Pre-team relational self-affirmation and team creative performance. The teams assigned to the treatment condition outperformed those in the control condition, $b=0.68$, $S E=0.32, p=.046$ (See Table 2), controlling for cohort, team size, mean age, and gender composition. The nature and significance of the results do not change when we do not include these controls.

***** Insert Table 2 about here

\section{Discussion}

Study 1 focused on a sample of senior leaders in a classroom setting and examined their team performance outcomes on a realistic 7-day crisis-simulation task. Teams consisting of members who relationally affirmed their self-views ten days prior to the start of the team task were rated by expert panels (who were blinded to the experimental condition) as performing better than teams consisting of members who did not do so. Thus, Hypothesis 2 is supported.

Although Study 1 demonstrated the team performance effect of pre-team relational selfaffirmation, we did not observe the team processes that took place during the 10-day period leading to the final briefings. This makes it difficult to pinpoint exactly what intrapsychic and interpersonal processes were influenced while team members collaborate on a creative task, as a consequence of relationally affirming one's self-views. We thus designed Study 2 to capture the 
specific intragroup processes of information exchange that take place in a team setting, and also whether the effects were mediated by individual members’ feelings of social worth.

\section{STUDY 2}

Study 2 focuses on the intrapsychic and intragroup processes that might improve creative performance of teams. We recruited virtual workers to work in teams in an online chat room. After being randomly assigned into either the treatment (pre-team relational self-affirmation) or control groups, they participated in a team decision-making task based on the hidden-profile task paradigm. We used a modified, virtual hidden profile task (Stasser and Titus, 1985) that allows team members to interact online using both communally and uniquely distributed information.

We predicted that relational self-affirmation prior to team entry would facilitate the team’s ability to exchange information, which spans from strategy planning to information gathering to information sharing. Study 2 allows us to test Hypotheses 1, 2, and 3, which predict that an increase in one's sense of social worth from affirming self-views at the individual level contributes to information exchange in teams.

In most hidden-profile tasks paradigm, finding the best option is difficult because it is not available to members during the task, and members have to depend on their recollection of the information while integrating pieces of unique information from different members to find the best alternative (Winquist and Larson, 1998). However, we allowed the information to be accessible during the team task to facilitate the detection of missing information, and to lead all teams to the optimal decision. Essentially, our design enabled us to identify how pre-team relational self-affirmation improves information exchange during the problem-solving task, while the outcome of the team process is kept identical. ${ }^{3}$

\footnotetext{
${ }^{3}$ Despite our intention to have the team's final decision fixed, a total of three teams (two from the treatment groups and one from the control groups) failed to identify the best option despite all information
} 


\section{Sample and Procedures}

We recruited study participants by posting an ad on Amazon’s Mechanical Turk. All participants were first asked to identify potential feedback providers who knew them well and could describe narratives when participants were at their best. Participants were encouraged to include a mix of contacts, including friends, mentors, family members, customers, and colleagues. These social network members were then invited to write up to three detailed narratives describing occasions when the participant made his or her most positive impact. Only the participants whose contacts provided at least three impact narratives were deemed eligible. A total of 123 participants (21 treatment vs. 20 control groups; 41 teams total) participated in a month-long longitudinal study $\left(M_{\text {age }}=32.78, S D_{a g e}=11.26,31 \%\right.$ male $)$ and received a $\$ 15$ Amazon.com gift card once they completed the follow-up online survey.

Group assignment and experimental manipulation. Once we randomly assigned eligible participants into three-person teams, the teams were invited to schedule a virtual chat room session through Chatzy.com at the same time. We then randomly assigned these teams into either treatment or control groups. Treatment groups received their impact narratives the night before their scheduled session, following the same procedure as in Study 1, while control groups received theirs after they completed the follow-up survey. The following is an example of an impact narrative, using pseudonyms:

Laura has good forethought for business and does anything and everything she can to help keep us employed. In 2012, when Hurricane Sandy hit the East coast, here in Florida

being available for the team task. The probability of solving the problem did not differ significantly across different conditions, $\mathrm{B}=-0.57, \mathrm{SE}=1.31, p=.661$. Although this analysis is not pertinent to testing our core hypothesis on information exchange, and the rate of failure is too low to be analyzed further, we repeated all our analyses, excluding teams that were not successful at creative problemsolving. This exclusion did not change the direction or significance of our results. 
we did not really think much of it. But Laura was obviously worried that it would impact her business, because a lot of our accounts receivables are in the NYC/New Jersey areas. She ended up borrowing from her retirement savings to keep the business going. I even suggested that maybe she could let the couple of part-timers go, but she responded that the people there always gave their best, so she wouldn't want to do anything less for them. It took about six months to get things back on track, but we all managed to keep our jobs thanks to Laura.

Another example is:

I first met Mike in the early 80's. He was in a wheel chair and smiling, I remember. When he could come to school, he was in pain but was full of grit. As teenagers, we did not see Mike as special; he wanted to be one of our classmates, and he was the one with a smile that could light up the room. Today, I realize just how much determination was transmitted in his smile.

Hidden profile task. As in the typical hidden profile task (Stasser and Titus, 1985), each participant was given a different set of data, and as a team they tried to collaborate and pool their information to effectively solve the problem. All participants received study instructions for the hidden profile task via email, and their receipt of the instructions was confirmed before the virtual team task. Participants were told to work together in a virtual chat room to solve a simulated business problem in order to evaluate how different factors impact team decisionmaking. We adapted a decision-making task for a four-person team in the Air Force, used in Graetz et al. (1998), to a three-person team task in which participants played the role of purchasing executives for a fictitious restaurant chain. Each participant was told to read the task instructions and provided with a unique checklist of the attributes satisfied by opening a branch 
in each of three fictitious locations, East Point Mall, Starlight Valley, and Cape James Beach (see Appendix B). They were instructed to read the checklist and keep it available for the team task. The checklist involved information that is common to all members of the team as well as information unique to each participant.

In the study, the total number of unique information cues was 16, and the total number of communal information cues was 14 . Table 3 describes how the information is actually distributed across three participants. Based on its overall profile, Starlight Valley satisfied the most criteria and should be selected first, followed next by Cape James Beach and then by East Point Mall. This conclusion is not apparent because the checklist differed for each participant. It was therefore necessary for team members to collaborate and combine information in order to correctly rank-order the different restaurant locations. Information about East Point Mall was made more available to each participant. Taken alone, the initial checklists for all participants support East Point Mall as most desirable, followed by Cape James Beach and Starlight Valley. Thus, only if all information regarding Starlight Valley was shared would teams arrive at the correct rank ordering.

\section{***** Insert Table 3 about here}

Once a team of three participants joined the chat room, our experimenter (blind to condition) introduced himself/herself as a fellow online worker and said that he/she had been instructed to be a time-keeper. The experimenter did not generate any new ideas or facilitate the discussion, but simply answered questions about how to use the chat room or the task. All teams were given a total of 10 minutes to review the instructions and 15 minutes to complete the team task. Participants also received five- and three-minute warnings. Once the team's decision was reached, the participants notified the moderator. During the discussion, all participants had 
access to their own checklist, although they were instructed that their checklist should be kept private and thus not sent or displayed to other team members. All virtual discussions among participants were captured in the text format by the experimenter for our analyses.

Follow-up survey. Following this team-based task, all participants were instructed to leave the chat room and begin the follow-up survey measuring individual members' feelings of social worth independently. We measured our proposed mediator - one’s generalized feelings of social worth - after the dependent measures. This choice was necessary because drawing participants' attention to the source of their emotional states can eliminate the impact of such feelings on cognition and behavior (Schwarz \& Clore, 1983; Schwarz, 1999). Thus, participants were not asked about their feelings of social worth until after they received impact narratives and completed the team task.

\section{Measures}

Information exchange in teams. The two coders read the chat transcripts in their entirety, and rated a random sample of the chat logs for the unique and communal cues exchanged (Stasser and Titus, 1985), with 10\% of the data overlapping. We used two measures (information gathering and sharing) as a proxy for the information exchange. For a measure of information sharing, we used the number of unique and communal cues as dependent measures (average ICC1 $=.75$, ICC2 $=.83, \mathrm{R}_{\mathrm{wg}}=.99$ ). Finally, they counted the number of times team members requested information (Emich, 2014). For information gathering, we draw from Flammer (1981) to make a distinction between direct and indirect requests for information. Direct information requests refer to a time when a team member addresses another person or the team about a specific piece of information (e.g., “A27, do you have anything on East Point?”). On the other hand, indirect information requests are made by either probing for more information 
or setting the stage for someone else on the team to feel obligated to offer information (e.g., "I am missing information for East Point”). We used the number of direct and indirect informationseeking behaviors as dependent measures (average ICC1 $=.82$, ICC2 $=.89, \mathrm{R}_{\mathrm{wg}}=.96$ ).

Feelings of social worth. Each participant rated their sense of social worth using a 3-item scale (Grant \& Gino, 2010) that included “I feel valued as a person,” “I feel appreciated as an individual,” and “I feel that I made a positive difference in others' lives” ( 1 = Strongly disagree, 7 = Strongly agree; $\alpha=.90)$. We averaged the team members’ ratings once they achieved good interrater reliability (average ICC1 $=.31, \mathrm{ICC} 2=.57, \mathrm{R}_{\mathrm{wg}}=.98$ ).

\section{Results}

Data analysis strategy. Similar to Study 1, we compared the team-level outcomes between treatment and control groups. For the individual-level data (i.e., feelings of social worth), we used hierarchical linear modeling (HLM) to account for the nesting effect (i.e., team members were nested in a team, which violates the assumption of independence of observation). This method provides unbiased estimates of standard errors (Raudenbush and Bryk, 2002). For the mediation analysis, we averaged the individual-level data at the team level, such that we can test the hypothesis that members' average level of social worth in a given team explains the relationship between pre-team relational self-affirmation and information exchange in teams. Although this study was conducted anonymously in a virtual setting, we accounted for mean age and gender composition in all statistical analyses, consistent with Study 1 (Polzer, Milton, and Swann, 2002; Woolley et al., 2010). Team size and timing of the session were not included, as they did not vary across different teams in this study. We report means, standard deviations, and zero-order correlations among the key variables in Table 4. 
Pre-team relational self-affirmation and information exchange in teams. We tested that pre-team relational self-affirmation increases quality of information exchange, based on how often team members shared unique cues, and how often they requested direct information from others. The treatment effect on the number of unique cues shared was positive and significant, b $=1.78, S E=0.78, p=.029$, while the effect on the number of communal cues was not statistically significant, $\mathrm{b}=-0.89, \mathrm{SE}=0.63, p=.166$. The treatment effect on the proportion of unique information shared to total information shared was positive and significant, b $=0.06, S E$ $=0.02, p=.003$. The total number of information cues shared did not differ between treatment and control conditions, $\mathrm{b}=0.83, S E=1.15, p=.441$.

Mirroring these results, the treatment effect on the number of direct requests was positive and significant, $\mathrm{b}=2.95, S E=1.06, p=.009$, while the effect on the number of indirect requests was negative and significant, $\mathrm{b}=-2.40, S E=0.85, p=.007$. The treatment effect on the proportion of direct information requests to total information requests was positive and significant, $\mathrm{b}=0.17, \mathrm{SE}=0.05, p=.002$. However, the total number of information requests made did not differ across treatment and control conditions, $\mathrm{b}=0.25, \mathrm{SE}=1.54, p=.869$.

These results suggest that teams with pre-team relational self-affirmation were more likely to share unique information (vs. communal information) and to directly ask for information (vs. indirect information requests).

$$
\text { ***** Insert Table } 5 \text { about here } * * * * *
$$

\section{Pre-team relational self-affirmation for feelings of social worth. In support for} Hypothesis 1, the treatment effect on feelings of social worth was positive and statistically significant, $\gamma=0.42, S E=0.17, p=.014$ (with mean age and gender composition held constant, $\gamma=0.41, S E=0.17, p=.018)$. 
Mediation analyses. We conducted two separate mediation analyses based on our prediction (Hypothesis 3). We used a bootstrap analysis for bias-corrected confidence intervals using 1,000 random samples (MacKinnon, Fairchild, \& Fritz, 2007; Shrout \& Bolger, 2002). Our hypotheses were partially supported. The 95\% bias-corrected confidence intervals for the size of the indirect effect on unique information sharing did not include zero ([.075, 2.172]). However, the confidence intervals for the size of the indirect effect on direct information request included zero $([-.828, .700])$. This suggests that social worth partially mediated the relationship between pre-team relational self-affirmation and unique information sharing, but not the direct information requests, as reported in Table 6.

***** Insert Table 6 about here $* * * * *$

\section{Discussion}

In Study 2, we attempted to capture ways in which teams can demonstrate high-quality information exchange and tested whether pre-team relational self-affirmation affected both intrapsychic and intragroup processes. Pre-team relational self-affirmation led to a member’s heightened feelings of social worth and better information exchange. Hypotheses 3 was partially supported; feelings of social worth partially mediated the relationship between pre-team relational self-affirmation and unique information sharing, but not direct information requests. This suggests a possibility that although more direct information requests were made in the treatment groups as compared to the control groups, our measures of information exchange may have been a function of distinctive mechanisms. That is, while sharing unique information cues could be explained by increased feelings of social worth, it is possible that direct requests were more frequently made due to one’s increased sense of self-efficacy, for example. 
Thus, Study 2 reveals the team's information exchange process by which pre-team relational self-affirmation can lead to better creative performance through successfully integrating unique perspectives. Study 2 also directly tested one psychological mechanism feelings of social worth - through which affirming one's self-views, we argued, is related to better information exchange in teams. These findings support our core argument that the feelings of social worth individuals have prior to joining a team matter, because they affect the team's idea-integration processes.

\section{GENERAL DISCUSSION}

Despite their potential to perform at high levels and make decisions that are better than those of individual team members, teams are often unable to capitalize on this potential. How can organizations prepare individual members to contribute the most to team discussions and outcomes? We proposed that pre-team relational self-affirmation through one's personal network can be an important element of preparation for contributing to a new team. In two studies, we showed how affirming team members' self-concept, prior to team formation, can offset the concerns for social acceptance they may have when negotiating their identity and exposing their unique perspectives to other team members. In addition, we identified and tested a mediating mechanism (feelings of social worth) that helped explain improvements in information exchange in teams. We thus empirically validate how pre-team relational self-affirmation can lead to sustained behavioral change (Roberts et al., 2005) by demonstrating positive changes in the ways in which individuals interact with their social system, as evidenced in team-level interactions. Our results provide critical evidence that the effect of a pre-team intervention can lead to both immediate and long-term outcomes in teams. 


\section{Theoretical Contributions}

The present research makes several contributions to existing research. First, our work contributes to a body of literature that examines why some teams achieve better outcomes than others (Ilgen et al., 2005; Hackman and Katz, 2010). Specifically, we unveil how pre-team relational self-affirmation, experienced prior to team formation, can carry over to an external social context and unlock team potential. The literature on team productivity loss (e.g., diminished idea-integration) has largely been explained by team-level structural factors governing the team process (Wittenbaum, Hollingshead, and Botero, 2004; Sohrab, Waller, and Kaplan, 2015). For example, the extant literature has identified the following factors: exposure to a minority’s dissenting voice (Nemeth and Wachtler, 1983; De Dreu and West, 2001; SchulzHardt et al., 2006), team-level reflexivity (Carter and West, 1998), and transactive memory systems (Stewart and Stasser, 1995; Liang, Moreland, and Argote, 1995; Gino et al., 2010).

Meanwhile, at an individual level, relatively little research has been conducted on the motivational factors that could reduce individual members' reluctance to communicate the information they have. ${ }^{4}$ Identifying and addressing the micro-level motivational factors that could influence team outcomes represents a significant gap in the literature (Sohrab, Waller, and Kaplan, 2015). Building on previous work that identified concerns for social acceptance as the psychological barrier that impairs productivity at the team level, our research emphasizes the role of both intrapsychic and intragroup processes in determining team outcomes (Mathieu et al., 2008). We advance the small group research literature by highlighting how a member-level motivation surfaces in the team formation phase and carries over to the team task. We identified

\footnotetext{
${ }^{4}$ There are, however, studies that focus on individual members' personality traits; shy individuals tended to perform worse in a team idea-generation task than in an individual idea-generation task (Camacho and Paulus, 1995), while conscientiousness, extraversion, and agreeableness predicted team creativityrelevant processes (Taggar, 2002).
} 
and tested a psychological mechanism (feelings of social worth) that explained improvements in creative problem-solving and quality of communication in teams.

Second, our research also advances self-affirmation theory by demonstrating how preteam relational self-affirmation can be used as a team-based intervention, to reduce members’ concerns about social acceptance prior to team entry and task completion. Scholars who study group affirmation have shown how a team's core value can be affirmed collectively after a team is formed and functioning together, as opposed to affirming individuals before the team entry. Affirming an important group value in teams has been shown to increase acceptance of threatening team information and reduce group-serving biases (Sherman et al., 2007). On the other hand, our research reveals that affirming an individual's self-views through one's own personal relationships prior to completing a team task can carry over to the group-level phenomenon. This suggests that helping individuals address their concerns for social acceptance prior to team entry can create valuable psychosocial resources for teams to reach their potential.

Lastly, our research also extends recent work by self-affirmation researchers in that we similarly focus on relational ingredient of the self-affirmation interventions and apply it into the team setting. Our intervention was targeted at using one’s existing social network to intensify feelings of social belonging, prior to team formation, so that each member contributes their best efforts and unique perspectives to the team. In a different domain, for example, Crocker, Niiya, and Mischkowski (2008) found that smokers who wrote about important values increased their positive other-directed feelings (such as love and connectedness with significant others), and this mediated the effect of self-affirmation on the increased likelihood of accepting threatening health information. In addition, Shnabel and colleagues (2013) examined the contents of selfaffirmation essays and found that the improvement in academic performance found among 
minority students was largely due to writing about social belonging. Their findings suggest that individuals reduced the sense of threat not by reflecting on their own personal strengths, but rather by reflecting on their valued social connections. Our work provides additional insights into how relational self-affirmation might relieve team members from being concerned about social acceptance, and thus improve their team performance.

\section{Practical Implications}

Our research identified a relatively low-cost intervention that enables individuals and organizations to institute high-impact changes that improve team performance. Our work highlights the importance of creating a point of reflection to remind individuals who they are when they are at their best and make positive contribution to others, prior to negotiating identity in a new team, because it results in better team outcomes in the long-term. In particular, when self-concept involves the idea of being socially valued by other people, individuals were able to function better in teams and help the team deliver on its potential.

Our research also resolves the important paradox that could arise from simply feeling good about ourselves. Nijstad et al. (2003) noted that there is an "illusion of group effectivity" that stems from the fact that people generally enjoy working in teams more than working individually, and expect their team performance to be more satisfactory than individual performance (Stroebe, Diehl, and Abakoumkin, 1992; Paulus and Dzindolet, 1993; Larey and Paulus, 1995; Heath and Jourden, 1997). One might argue that feeling good about oneself may lead to creating more "illusion" of group effectivity by having higher expectations about their performance than actually warranted. However, our results confirm that pre-team relational selfaffirmation reaches beyond a team-level illusion, and influenced information exchange and creative performance in teams. 
Relational Affirmation in Teams 31

\section{Limitations and Venues for Future Research}

One of the methodological strengths of this paper is that we used an experimental approach across two studies. This established the causal effect of pre-team relational affirmation. We also measured team performance using objective data (expert panel evaluation in Study 1, and trained coders’ ratings in Study 2) rather than relying on self-reported or recalled data. However, there are limitations of our studies that could be addressed in future research.

First, our research was conducted in the classroom and virtual setting, which qualifies our findings’ generalizability. Despite our best effort to simulate natural work settings, our results should be extended in different organizational settings. Next, we studied ad-hoc emergent teams without a designated leader rather than existing teams with intact team dynamics and relationships. Thus, future research should attempt to study preexisting work teams in organizations. Future research also should help identify critical boundary conditions to our findings; for example, some work may not allow employees sufficient autonomy to approach the team-based task differently because their roles have been defined strictly, thus reducing the effect of pre-team relational self-affirmation on team performance. Related, the organizational norms that influence the team’s psychological safety may also moderate the effects of pre-team relational self-affirmation.

Secondly, future research should examine the possibility that pre-team self-affirmation facilitates the process of self-verification among the team members after the team entry. While decades of past research have examined the relative strengths of positivity versus authenticity strivings when they are in conflict (Jones, 1973; Shrauger, 1975), we have shown that individuals can achieve both goals through reflected appraisals that give rise to feelings of social worth. Perhaps pre-team relational self-affirmation provides an opportunity for individuals to 
verify personal and social self-views simultaneously by receiving impact narratives about one's positive effects on others prior to team entry. In fact, previous research suggested that the compatibility between personal and social self-views allows team members to verify both selfviews simultaneously (Ely and Thomas, 2001). This interdependent nature of personal and social self-views may create an optimal mindset that helps teams engage in creative tasks, benefit from divergent thinking, and integrate disparate ideas (Swann et al., 2004).

\section{Conclusion}

Despite all the potential individuals have when they work together within a team, teams often perform poorly due to the lack of good communication and exchange of ideas among team members who are worried about conforming and fitting in rather than providing their unique data and perspectives. Pre-team relational self-affirmation allows employers and employees to capitalize on their psychosocial resources, and align their strengths closely with the work they do. This is because pre-team relational self-affirmation heightens individual members' sense of social worth, thus making them more open to share their unique information. Conceivably, preteam relational self-affirmation may lead to an upward spiral, in which the initial pre-team intervention increases team's creative performance, and the positive team dynamics that encourage information exchange reaffirm the employee's positive social self-views. 


\section{References}

Apker, J., K. M. Propp, W. S. Zabava Ford, and N. Hofmeister

2006 "Collaboration, credibility, compassion, and coordination: Professional nurse communication skill sets in health care team interactions.” Journal of Professional Nursing, 22: 180-189.

\section{Aronson, J., G. L. Cohen, and P. R. Nail}

1999 “Self-affirmation theory: A current perspective.” In E. Harmon-Jones and J. Mills (eds.), Advances in Experimental Social Psychology: 127-147. Washington, DC.

\section{Baron, R., N. Kerr, and N. Miller}

1992 Group Process, Group Decision, Group Action. Pacific Grove, California: Brooks.

\section{Barry, B. and G. L. Stewart}

1997 "Composition, process, and performance in self-managed groups: the role of personality." Journal of Applied Psychology, 82: 62-78.

Baumeister, R. F.

1982. "A self-presentational view of social phenomena." Psychological Bulletin, 91: 3-26.

\section{Baumeister, R. F.}

1986. Identity: Cultural change and the struggle for self. Oxford University Press.

Baumeister, R. F., and M. R. Leary

1995 "The need to belong: Desire for interpersonal attachments as a fundamental human motivation.” Psychological Bulletin, 117: 497-529.

\section{Brown, V. R., and P. B. Paulus}

2002 "Making group brainstorming more effective: Recommendations from an associative memory perspective.” Current Directions in Psychological Science, 11: 208-212.

\section{Camacho, L. M., and P. B. Paulus}

1995 “The role of social anxiousness in group brainstorming.” Journal of Personality and Social Psychology, 68: 1071-1080.

\section{Carter, S. M., and M. A. West}

1998 "Reflexivity, effectiveness, and mental health in BBC-TV production teams." Small Group Research, 29: 583-601.

\section{Carver, C. S., and M. F. Scheier}

1981 “The self-attention-induced feedback loop and social facilitation.” Journal of Experimental Social Psychology, 17: 545-568.

\section{Chaiken, S., and C. Stangor}

1987 “Attitudes and attitude change.” Annual Review of Psychology, 38: 575-630. 
Cohen, G. L., and D. K. Sherman

2014 "The psychology of change: Self-affirmation and social psychological intervention." Annual Review of Psychology, 65: 333-371.

Cooley, C. H.

1902. Human Nature and the Social Order. New York, NY: Schocken Books.

Crocker, J., Niiya, Y. and Mischkowski, D.

2008 "Why does writing about important values reduce defensiveness? Self-affirmation and the role of positive other-directed feelings." Psychological Science, 19: 740-747.

Cruz, M. G., F. J. Boster, and J. I. Rodríguez

1997 "The impact of group size and proportion of shared information on the exchange and integration of information in groups.” Communication Research, 24: 291-313.

De Dreu, C. K. W., and M. A. West

2001 "Minority dissent and team innovation: The importance of participation in decision making.” Journal of Applied Psychology, 86: 1191-1201.

Diehl, M., and W. Stroebe

1987 "Productivity loss in brainstorming groups: Toward the solution of a riddle." Journal of Personality and Social Psychology, 53: 497-509.

Durham, C. C., E. A. Locke, J. M. Poon, and P. L. McLeod

2000 "Effects of group goals and time pressure on group efficacy, information-seeking strategy, and performance." Human Performance, 13: 115-138.

Dutton, J. E., L. M. Roberts, and J. Bednar

2010 "Pathways for positive identity construction at work: four types of positive identity and the building of social resources.” Academy of Management Review, 35: 265-293.

Edmondson, A.

1999 "Psychological safety and learning behavior in work teams.” Administrative Science Quarterly, 44: 350-383.

Eisenhardt, K. M., and J. A. Martin

2000 “Dynamic capabilities: what are they?” Strategic Management Journal, 21: 1105-1121.

Elliott, G. C., M. F. Colangelo, and R. J. Gelles

2005 "Mattering and suicide ideation: Establishing and elaborating a relationship." Social Psychology Quarterly, 68: 223-238.

Ely, R. J., and D. A. Thomas

2001 "Cultural diversity at work: The effects of diversity perspectives on work group processes and outcomes.” Administrative Science Quarterly, 46: 229-273. 


\section{Emich, K. J.}

2014 "Who's bringing the donuts: The role of affective patterns in group decision making." Organizational Behavior and Human Decision Processes, 124: 122-132.

Flammer, A.

1981 “Towards a theory of question asking.” Psychological Research, 43: 407-420.

Flynn, F. J., and V. K. B. Lake

2008 "If you need help, just ask: Underestimating compliance with direct requests for help." Journal of Personality and Social Psychology, 95: 128-143.

\section{Gardner, H. K., F. Gino, and B. R. Staats}

2012 "Dynamically integrating knowledge in teams: Transforming resources into performance.” Academy of Management Journal, 55: 998-1022.

\section{Gino, F., L. Argote, E. Miron-Spektor, and G. Todorova}

2010 "First, get your feet wet: The effects of learning from direct and indirect experience on team creativity.” Organizational Behavior and Human Decision Processes, 111: 102-115.

Graetz, K. A., E. S. Boyle, C. E. Kimble, P. Thompson, and J. L. Garloch

1998 "Information sharing in face-to-face, teleconferencing, and electronic chat groups." Small Group Research, 29: 714-743.

\section{Gruenfeld, D. H., E. A. Mannix, K. Y. Williams, and M. A. Neale}

1996 "Group composition and decision making: How member familiarity and information distribution affect process and performance.” Organizational Behavior and Human Decision Processes, 67: 1-15.

Hackman, J. R., and N. Katz

2010 Group Behavior and Performance. Hoboken, NJ, USA: John Wiley \& Sons, Inc.

\section{Heath, C., and F. J. Jourden}

1997 "Illusion, disillusion, and the buffering effect of groups." Organizational Behavior and Human Decision Processes, 69: 103-116.

Henningsen, D. D., and M. L. M. Henningsen

2004 "The effect of individual difference variables on information sharing in decision-making groups.” Human Communication Research, 30: 540-555.

\section{Hinsz, V. B., R. S. Tindale, and D. A. Vollrath}

1997 “The emerging conceptualization of groups as information processors.” Psychological Bulletin, 121: 43-64.

Hyatt, D. E. and T. M. Ruddy

1997 "An examination of the relationship between work group characteristics and 
performance: Once more into the breech." Personnel Psychology, 50: 553-585.

\section{Ibarra, H., and R. Barbulescu}

2010 "Identity as narrative: Prevalence, effectiveness, and consequences of narrative identity work in macro work role transitions.” Academy of Management Review, 35: 135-154.

Ilgen, D. R., J. R. Hollenbeck, M. Johnson, and D. Jundt

2005 "Teams in organizations: From Input-Process-Output models to IMOI models.” Annual Review of Psychology, 56: 517-543.

Jones, S. C.

1973 "Self- and interpersonal evaluations: Esteem theories versus consistency theories." Psychological Bulletin, 79: 185-199.

Katz, R.

1985 “Organizational stress and early socialization experiences.” In T. A. Beehr and R. S. Bhagat (eds.), Human Stress and Cognition in Organizations: 117-139. New York: Wiley: Wiley-Interscience.

Lamm, H., and G. Trommsdorff

1973 "Group versus individual performance on tasks requiring ideational proficiency (brainstorming): A review.” European Journal of Social Psychology, 3: 361-388.

\section{Larey, T. S., and P. B. Paulus}

1995 "Social comparison and goal setting in brainstorming groups.” Journal of Applied Social Psychology, 25: 1579-1596.

\section{Larson, J. R., P. G. Foster-Fishman, and C. B. Keys}

1994 "Discussion of shared and unshared information in decision-making groups." Journal of Personality and Social Psychology, 67: 446-461.

\section{Liang, D. W., R. Moreland, and L. Argote}

1995 "Group versus individual training and group performance: The mediating role of transactive memory.” Personality and Social Psychology Bulletin, 21: 384-393.

\section{Littlepage, G., E. B. Perdue, and D. K. Fuller}

2012 "Choice of information to discuss: Effects of objective validity and social validity." Small Group Research, 43: 252-274.

Malone, T. W., and K. Crowston

1994 "The interdisciplinary study of coordination." ACM Computing Surveys (CSUR), 26: 87$-119$.

Mathieu, J., M. T. Maynard, T. Rapp, and L. Gilson

2008 "Team effectiveness 1997-2007: A review of recent advancements and a glimpse into the future.” Journal of Management, 34: 410-476. 
McAdams, D. P.

1988 “Biography, narrative, and lives: An Introduction.” Journal of Personality, 56: 1-18.

McAdams, D. P.

1996 "Personality, modernity, and the storied self: A contemporary framework for studying persons.” Psychological Inquiry, 7: 295-321.

McAdams, D. P., and E. de St Aubin

1992 "A theory of generativity and its assessment through self-report, behavioral acts, and narrative themes in autobiography.” Journal of Personality and Social Psychology, 62: 1003-1015.

McGrath, J. E., and L. Argote, L.

2001 "Group processes in organizational contexts." Blackwell Handbook of Social Psychology: Group Processes, 603-627.

McQueen, A., and W. M. P. Klein

2006 “Experimental manipulations of self-affirmation: A systematic review.” Self and Identity, 5: 289-354.

Mohrman, S. A., S. G. Cohen, and A. M. Morhman Jr.

1995 Designing team-based organizations: New forms for knowledge work. Jossey-Bass.

Mullen, B., C. Johnson, and E. Salas

1991 "Productivity loss in brainstorming groups: A meta-analytic integration." Basic and Applied Social Psychology, 12: 3-23.

\section{Nemeth, C. J., and J. Wachtler}

1983 “Creative problem solving as a result of majority vs. minority influence.” European Journal of Social Psychology, 13: 45-55.

Neuman, G. A., and J. Wright

1999 "Team effectiveness: Beyond skills and cognitive ability.” Journal of Applied Psychology, 84: 376-389.

Nijstad, B. A., E. F. Rietzschel, and W. Stroebe

2006 “Four principles of group creativity.” In L. L. Thompson and H. S. Choi (eds.), 161-179. Hillsdale, NJ: Lawrence Erlbaum Associates.

Nijstad, B. A., W. Stroebe, and H. F. M. Lodewijkx

2003 "Production blocking and idea generation: Does blocking interfere with cognitive processes?.” Journal of Experimental Social Psychology, 39: 531-548.

Pauhus, P. B., M. T. Dzindolet, G. Poletes, and L. M. Camacho

1993 "Perception of performance in group brainstorming: The illusion of group productivity." 
Personality and Social Psychology Bulletin, 19: 78-89.

Paulus, P. B., and M. T. Dzindolet

1993 "Social influence processes in group brainstorming.” Journal of Personality and Social Psychology, 64: 575-586.

Polzer, J. T., L. P. Milton, and W. B. Swann.

2002. "Capitalizing on diversity: Interpersonal congruence in small work groups." Administrative Science Quarterly, 47: 296-324.

Raudenbush, S. W., and A. S. Bryk

2002 Hierarchical Linear Models. SAGE.

Roberts, L. M., J. E. Dutton, G. M. Spreitzer, E. D. Heaphy, and R. E. Quinn

2005 "Composing the reflected best-self portrait: Building pathways for becoming extraordinary in work organizations.” Academy of Management Review, 30: 712-736.

\section{Rosenberg, M., and B. C. McCullough}

1981 "Mattering: Inferred significance and mental health among adolescents.” Research in Community \& Mental Health. JAI Press, Inc.

Ryan, R. M., and E. L. Deci

2000 "Intrinsic and extrinsic motivations: Classic definitions and new directions." Contemporary Educational Psychology, 25: 54-67.

\section{Sanna, L. J., and R. L. Shotland}

1990 "Valence of anticipated evaluation and social facilitation.” Journal of Experimental Social Psychology, 26: 82-92.

Sarbin, T. R.

1986 Narrative Psychology: the Storied Nature of Human conduct. Praeger. New York.

Schulz-Hardt, S., F. C. Brodbeck, A. Mojzisch, R. Kerschreiter, and D. Frey

2006 "Group decision making in hidden profile situations: Dissent as a facilitator for decision quality.” Journal of Personality and Social Psychology, 91: 1080-1093.

Schwarz, N., and G. L. Clore.

1983 "Mood, misattribution, and judgments of well-being: Informative and directive functions of affective states." Journal of Personality and Social Psychology, 45, 513-523.

\section{Schwarz, $\mathbf{N}$.}

1999 "Self-reports: How the questions shape the answers" American Psychologist, 54, 93-105.

Sherman, D. K., and G. L. Cohen

2002 "Accepting threatening information: Self-affirmation and the reduction of defensive biases.” Current Directions in Psychological Science, 11: 119-123. 
Sherman, D. K., Z. Kinias, B. Major, H. S. Kim, and M. Prenovost

2007 "The group as a resource: Reducing biased attributions for group success and failure via group affirmation.” Personality and Social Psychology Bulletin, 33: 1100-1112. SAGE Publications.

Shnabel, N., V. Purdie-Vaughns, J. E. Cook, J. Garcia, and G. L. Cohen

2013 "Demystifying values-affirmation interventions: Writing about social belonging is a key to buffering against identity threat.” Personality and Social Psychology Bulletin, 39: 663676.

\section{Shrauger, J. S.}

1975 "Responses to evaluation as a function of initial self-perceptions." Psychological Bulletin, 82: 581-596.

Shrauger, J. S., and T. J. Schoeneman

1979 "Symbolic interactionist view of self-concept: Through the looking glass darkly." Psychological Bulletin, 86: 549-573.

\section{Singer, J. A., and P. Salovey}

1983 Remembered Self. Simon and Schuster.

Sohrab, S. G., M. J. Waller, and S. Kaplan

2015 "Exploring the hidden-profile paradigm: A literature review and analysis.” Small Group Research, 46: 489-535.

Stasser, G., and W. Titus

1985 "Pooling of unshared information in group decision making: Biased information sampling during discussion.” Journal of Personality and Social Psychology, 48: 14671478.

Stasser, G., and W. Titus

2003 "Hidden profiles: A brief history.” Psychological Inquiry, 14: 304-313.

Steele, C. M.

1988 "The psychology of self-affirmation: Sustaining the integrity of the self." Advances in Experimental Social Psychology, 261-302.

\section{Stewart, D. D., and G. Stasser}

1995 "Expert role assignment and information sampling during collective recall and decision making.” Journal of Personality and Social Psychology, 69: 619-628.

\section{Stewart, D. D., and G. Stasser}

1998 "The sampling of critical, unshared information in decision-making groups: the role of an informed minority.” European Journal of Social Psychology, 28: 95-113. John Wiley \& Sons, Ltd. 
Stout, R. J., J. A. Cannon-Bowers, E. Salas, and D. M. Milanovich

1999 "Planning, shared mental models, and coordinated performance: An empirical link is established. Human Factors: The Journal of the Human Factors and Ergonomics Society, 41: 61-71.

Stroebe, W., M. Diehl, and G. Abakoumkin

1992 “The Illusion of group effectivity.” Personality and Social Psychology Bulletin, 18: 643650.

Swann, W. B., J. T. Polzer, D. C. Seyle, and S. J. Ko

2004 "Finding value in diversity: Verification of personal and social self-views in diverse groups.” Academy of Management Review, 29: 9.

\section{Swann, W. B., Jr, V. S. Y. Kwan, J. T. Polzer, and L. P. Milton}

2003 "Fostering group identification and creativity in diverse groups: The role of individuation and self-verification.” Personality and Social Psychology Bulletin, 29: 1396-1406.

Taggar, S.

2002 "Individual creativity and group ability to utilize individual creative resources: A multilevel model.” Academy of Management Journal, 45: 315-330.

Tannenbaum, S. I., R. L. Beard, and E. Salas

1992 "Team building and its influence on team effectiveness: An examination of conceptual and empirical developments." Advances in Psychology, 82: 117-153.

Taylor, D. W., P. C. Berry, and C. H. Block

1958 "Does group participation when using brainstorming facilitate or inhibit creative thinking.” Administrative Science Quarterly, 3: 23-47.

Tesluk, P. E., J. L. Farr, and S. R. Klein, S.R.

1997 "Influences of organizational culture and climate on individual creativity." The Journal of Creative Behavior, 31: 27-41.

Van Mannen, J.

1977 "Experiencing organization: notes on the meaning of careers and socialization.” In J. Van Mannen (ed.), Organizational Careers: 15-45. New York: Wiley.

Wicklund, R. A., and Gollwitzer, P. M., 1982. Symbolic Self-Completion. Hillsdale, NJ: Erlbaum.

Winquist, J. R., and J. R. J. Larson

1998 "Information pooling: When it impacts group decision making.” Journal of Personality and Social Psychology, 74: 371-377.

Wittenbaum, G. M., A. B. Hollingshead, and I. C. Botero 
2004 "From cooperative to motivated information sharing in groups: moving beyond the hidden profile paradigm.” Communication Monographs, 71: 286-310.

Wittenbaum, G. M., A. P. Hubbell, and C. Zuckerman

1999 "Mutual enhancement: Toward an understanding of the collective preference for shared information.” Journal of Personality and Social Psychology, 77: 967-978.

Wittenbaum, G. M., and G. Stasser

1996 "Management of information in small groups.” In J. Nye and A. Brower (eds.), What's Social About Social Cognition? Research on Socially Shared Cognition in Small Groups: 398. Thousand Oaks, CA: Management Inform. Small Groups.

Woolley, A. W., C. F. Chabris, A. Pentland, N. Hashmi, and T. W. Malone

2010 "Evidence for a collective intelligence factor in the performance of human groups." Science, 330: 686-688.

Wrzesniewski, A., Dutton, J.E. and Debebe, G.

2003. "Interpersonal sensemaking and the meaning of work." Research in Organizational Behavior, 25: 93-135.

Zalesny, M. D., E. Salas, and C. Prince

1995 "Conceptual and measurement issues in coordination: Implications for team behavior and performance.” Research in Personnel and Human Resources Management, 13: 81-115. 
TABLE 1

Means, Standard Deviations, and Zero-order Correlations among Key Variables, Study 1

\begin{tabular}{llcccccc}
\hline & Variables & Mean & SD & $\mathbf{1}$ & $\mathbf{2}$ & $\mathbf{3}$ & $\mathbf{4}$ \\
\hline 1 & Treatment (vs. Control) & 0.524 & 0.050 & & & & \\
2 & Team Creative Performance & 0 & 1 & $0.351^{*}$ & & & \\
3 & Team Size & 5.952 & 0.661 & -0.143 & -0.184 & & \\
4 & Mean Age & 48.24 & 3.370 & -0.035 & 0.154 & $-0.275 \wedge$ & \\
5 & Gender Composition & 0.276 & 0.098 & -0.160 & 0.128 & 0.061 & -0.055 \\
\hline
\end{tabular}

Note. Team creative performance was standardized using z-scores. ${ }^{* * *} p<0.001,{ }^{* *} p<0.01,{ }^{*} p<0.05, \wedge p<0.10$. 
TABLE 2

Multiple Regression Analyses for Expert-rated Team Outcomes, Study 1

\begin{tabular}{|c|c|c|}
\hline \multirow[t]{2}{*}{ Predictor Variables } & \multicolumn{2}{|c|}{$\begin{array}{l}\text { Team Creative } \\
\text { Performance }\end{array}$} \\
\hline & $\mathrm{B}$ & SE \\
\hline Treatment (vs. Control) & $0.679 *$ & 0.325 \\
\hline Team Size & -0.133 & 0.269 \\
\hline Mean Age & 0.054 & 0.051 \\
\hline Gender Composition & 1.465 & 2.164 \\
\hline Panel \#2 & 0.127 & 0.596 \\
\hline Panel \#3 & -0.531 & 0.595 \\
\hline Panel \#4 & -0.202 & 0.686 \\
\hline Panel \#5 & 0.429 & 0.697 \\
\hline Panel \#6 & -0.288 & 0.690 \\
\hline Panel \#7 & -0.598 & 0.677 \\
\hline Panel \#8 & 0.127 & 0.670 \\
\hline Panel \#9 & -0.708 & 0.730 \\
\hline $\mathrm{N}$ & \multicolumn{2}{|c|}{42} \\
\hline Overall F & \multicolumn{2}{|c|}{1.11} \\
\hline R-squared & \multicolumn{2}{|c|}{0.314} \\
\hline Adj R-squared & \multicolumn{2}{|c|}{0.031} \\
\hline Root MSE & \multicolumn{2}{|c|}{0.984} \\
\hline
\end{tabular}

Note. B refers to an unstandardized regression coefficient, and panel refers to group of experts who evaluated work team (dummycoded). ${ }^{* * *} p<0.001,{ }^{* *} p<0.01,{ }^{*} p<0.05, \wedge p<0.10$. 
TABLE 3

Information Distribution, Study 2

\begin{tabular}{|c|c|c|c|c|c|c|c|c|c|}
\hline & \multicolumn{3}{|c|}{$\begin{array}{l}\text { East Point } \\
\quad \text { Mall }\end{array}$} & \multicolumn{3}{|c|}{$\begin{array}{l}\text { Starlight } \\
\text { Valley }\end{array}$} & \multicolumn{3}{|c|}{$\begin{array}{c}\text { Cape James } \\
\text { Beach }\end{array}$} \\
\hline Criterion & P1 & $\mathbf{P 2}$ & P3 & P1 & $\mathbf{P 2}$ & P3 & P1 & $\mathbf{P 2}$ & $\mathbf{P 3}$ \\
\hline At least 50 parking spaces & $\mathrm{Y}$ & $\mathrm{Y}$ & $\mathrm{Y}$ & $\mathrm{Y}$ & & & $\mathrm{N}$ & $\mathrm{N}$ & \\
\hline Larger than 2,000 square feet & $\mathrm{N}$ & & & & $\mathrm{Y}$ & & & & $\mathrm{N}$ \\
\hline Purchasing cost of less than $\$ 1 \mathrm{MM}$ & & $\mathrm{N}$ & & & & $\mathrm{Y}$ & & $\mathrm{Y}$ & \\
\hline $\begin{array}{l}\text { No more than } 2 \text { direct competitors in } \\
\text { vicinity }\end{array}$ & & & $\mathrm{N}$ & & & $\mathrm{Y}$ & $\mathrm{Y}$ & $\mathrm{Y}$ & \\
\hline Substantial foot traffic & $\mathrm{Y}$ & $\mathrm{Y}$ & $\mathrm{Y}$ & & $\mathrm{Y}$ & & & $\mathrm{Y}$ & $\mathrm{Y}$ \\
\hline Low maintenance costs & & & $\mathrm{N}$ & $\mathrm{Y}$ & & & & & $\mathrm{Y}$ \\
\hline Large tourist population & $\mathrm{N}$ & $\mathrm{N}$ & $\mathrm{N}$ & & $\mathrm{Y}$ & & $\mathrm{Y}$ & $\mathrm{Y}$ & $\mathrm{Y}$ \\
\hline Large student population & $\mathrm{Y}$ & $\mathrm{Y}$ & $\mathrm{Y}$ & $\mathrm{N}$ & $\mathrm{N}$ & $\mathrm{N}$ & $\mathrm{N}$ & & \\
\hline Quick access to waste disposal & $\mathrm{Y}$ & $\mathrm{Y}$ & $\mathrm{Y}$ & $\mathrm{Y}$ & & & $\mathrm{N}$ & & $\mathrm{N}$ \\
\hline $\begin{array}{l}\text { Large population of employable } \\
\text { individuals }\end{array}$ & $\mathrm{Y}$ & $\mathrm{Y}$ & $\mathrm{Y}$ & $\mathrm{N}$ & $\mathrm{N}$ & $\mathrm{N}$ & $\mathrm{Y}$ & & $\mathrm{Y}$ \\
\hline True Profile & & $+5 /-5$ & & & $+8 /-2$ & & & $+6 /-4$ & \\
\hline
\end{tabular}

Note. P1 denotes Participant No. 1, and so forth. 
TABLE 4

Means, Standard Deviations, and Zero-order Correlations among Key Variables, Study 2

\begin{tabular}{|c|c|c|c|c|c|c|c|c|c|c|c|c|}
\hline & Variables & Mean & SD & 1 & 2 & 3 & 4 & 5 & 6 & 7 & 8 & 9 \\
\hline 1 & $\begin{array}{l}\text { Treatment (vs. } \\
\text { Control) }\end{array}$ & 0.512 & 0.506 & & & & & & & & & \\
\hline 2 & $\begin{array}{l}\text { Unique Information } \\
\text { Cues }\end{array}$ & 13.804 & 2.61 & $0.361 *$ & & & & & & & & \\
\hline 3 & $\begin{array}{l}\text { Communal } \\
\text { Information Cues }\end{array}$ & 12.756 & 2.01 & -0.218 & 0.229 & & & & & & & \\
\hline 4 & $\begin{array}{l}\text { Total Information } \\
\text { Cues }\end{array}$ & 26.561 & 3.64 & 0.139 & $0.843 * * *$ & $0.716^{* * *}$ & & & & & & \\
\hline 5 & $\begin{array}{l}\text { Indirect Information } \\
\text { Requests }\end{array}$ & 4.707 & 3.1 & $-0.396 *$ & $-0.285^{\wedge}$ & -0.060 & -0.238 & & & & & \\
\hline 6 & $\begin{array}{l}\text { Direct Information } \\
\text { Requests }\end{array}$ & 8.122 & 3.75 & $0.414^{* *}$ & 0.089 & $-0.361 *$ & -0.135 & -0.126 & & & & \\
\hline 7 & $\begin{array}{l}\text { Total Information } \\
\text { Requests }\end{array}$ & 12.829 & 4.555 & 0.071 & -0.121 & $-0.338^{*}$ & $-0.273^{\wedge}$ & $0.577 * * *$ & $\begin{array}{l}0.738 * * \\
*\end{array}$ & & & \\
\hline 8 & Sense of Social Worth & 3.845 & 0.59 & $0.364 *$ & $0.490 * *$ & 0.068 & $0.389 *$ & $-0.348 *$ & 0.167 & -0.100 & & \\
\hline 9 & Mean Age & 32.691 & 6.891 & 0.128 & 0.132 & -0.034 & 0.076 & -0.162 & 0.223 & 0.073 & 0.134 & \\
\hline 10 & Gender Composition & 0.683 & 0.307 & 0.055 & 0.192 & 0.184 & 0.240 & $0.310 *$ & -0.154 & 0.084 & 0.038 & 0.0203 \\
\hline
\end{tabular}

Note. ${ }^{* * *} p<0.001,{ }^{* *} p<0.01, * p<0.05, \wedge p<0.10$. 
TABLE 5

Multiple Regression Analyses for Measures of Information Exchange, Study 2

\begin{tabular}{|c|c|c|c|c|}
\hline \multirow{3}{*}{ Predictor Variables } & \multicolumn{4}{|c|}{ Information Exchange } \\
\hline & \multicolumn{2}{|c|}{ Unique Information Sharing } & \multicolumn{2}{|c|}{ Direct Information Request } \\
\hline & B & SE & B & SE \\
\hline Treatment (vs. Control) & $1.782 *$ & 0.782 & $2.954 * *$ & 1.066 \\
\hline Mean Age & 0.021 & 0.058 & 0.118 & 0.08 \\
\hline Gender Composition & 1.373 & 1.304 & -0.269 & 1.777 \\
\hline $\mathrm{N}$ & \multicolumn{2}{|c|}{41} & \multicolumn{2}{|c|}{41} \\
\hline $\mathrm{F}(3,37)$ & \multicolumn{2}{|c|}{$2.41^{\wedge}$} & \multicolumn{2}{|c|}{$4.06 *$} \\
\hline R-squared & \multicolumn{2}{|c|}{0.163} & \multicolumn{2}{|c|}{0.247} \\
\hline Adjusted R-squared & \multicolumn{2}{|c|}{0.095} & \multicolumn{2}{|c|}{0.186} \\
\hline Root MSE & \multicolumn{2}{|c|}{2.482} & \multicolumn{2}{|c|}{3.382} \\
\hline
\end{tabular}

Note. B refers to an unstandardized regression coefficient. Unique information sharing indicates the number of unique information cues shared, and direct information requests indicates the number of direct information requests made. ${ }^{* * *} p<0.001, * * p<0.01$, ${ }^{*} p<0.05, \wedge p<0.10$. 
TABLE 6

Mediation Analyses, Study 2

\begin{tabular}{|c|c|c|c|c|c|c|}
\hline \multirow{3}{*}{ Path } & \multicolumn{6}{|c|}{ Information Exchange } \\
\hline & \multicolumn{3}{|c|}{ Unique Information Sharing } & \multicolumn{3}{|c|}{ Direct Information Request } \\
\hline & Effect & $\mathrm{SE}$ & $\mathrm{CI}$ & Effect & $\mathrm{SE}$ & $\mathrm{CI}$ \\
\hline Path A (IV --> DV) & 0.412 & 0.179 & & 0.412 & 0.179 & \\
\hline Path B (MV --> DV) & 1.803 & 0.662 & & 0.005 & 0.990 & \\
\hline Path C (Total Effect) & 1.782 & 0.782 & & 2.954 & 1.066 & \\
\hline Path C' (Direct Effect) & 1.039 & 0.772 & & 2.952 & 1.155 & \\
\hline Indirect Effect & 0.743 & 0.491 & $0.075,2.172$ & 0.002 & 0.369 & $-0.828,0.700$ \\
\hline
\end{tabular}

Note. CI refers to the bias-corrected 95\% confidence interval; effect refers to the effect estimate using 1,000 bootstrap samples; estimates with CIs that do not include zero are statistically significant and bolded. 
FIGURE 1

A multi-level model of pre-team relational self-affirmation

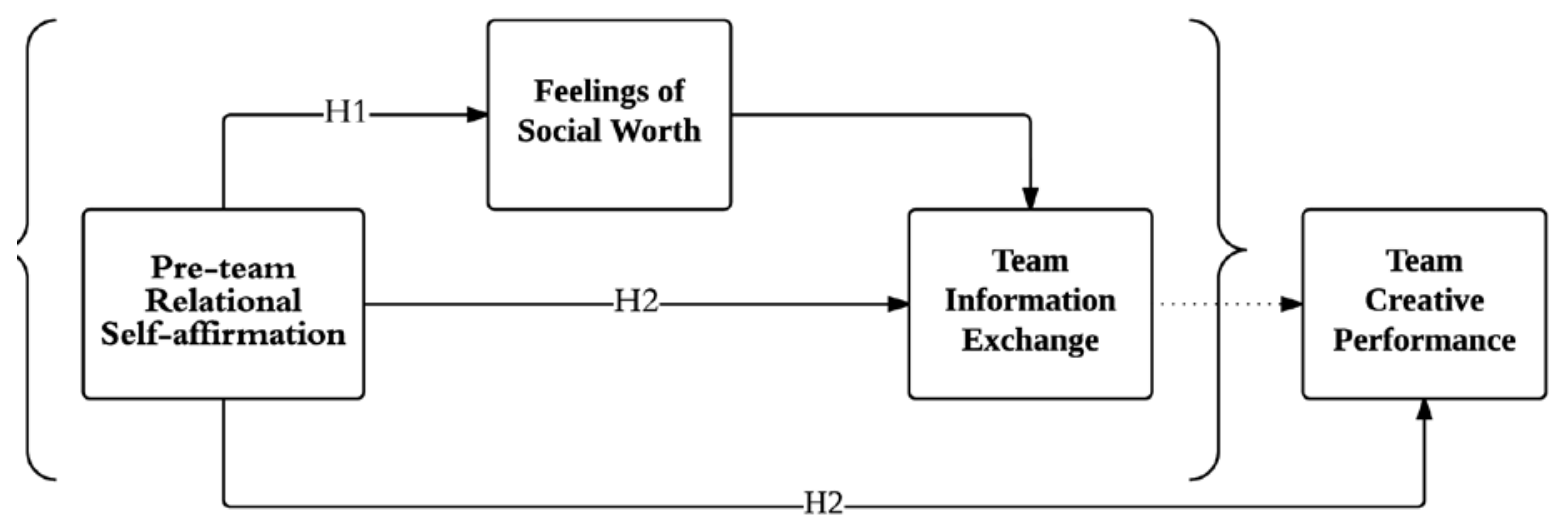

Note. Dashed line is not tested. 
Best Self in Teams 49

\section{APPENDIX A}

\section{Crisis simulation task for the Middle East Respiratory Syndrome (MERS)}

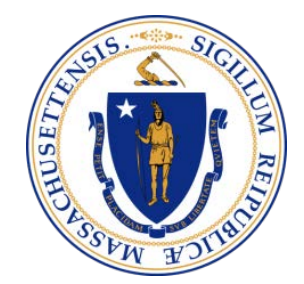

Senior Executive Fellows Program

October 2014

You are a member of a small interagency team (composed of members of your SEF discussion group) working in Massachusetts state government. With the discovery of a dangerous coronavirus here in the Commonwealth, the Governor's chief of staff has contacted your team leader and tasked the group to monitor progress of the virus, assess the threat to public health and safety, identify options for action by public health and emergency management authorities, and recommend a preferred course of action. You should complete your assessment prior to Friday, October 24.

The chief of staff explains that the Bay State Medical Center in Springfield, MA admitted two patients Saturday evening with intense flu like symptoms. Both were in respiratory distress. As it happened there was a young Saudi medical doctor working in the Bay State Emergency Room as part of his medical residency. He suggested that the patients might be suffering from the Middle East Respiratory Syndrome (MERS-CoV), a rare, recently discovered coronavirus, heretofore only seen in the Middle East, with a few cases in Europe.

Massachusetts Public Health Commissioner Cheryl Bartlett spoke this morning with Dr Tom Frieden, Director of the US Center for Disease Control (CDC), the nation's leading public health agency. Dr Frieden shared with Commissioner Bartlett what is known about MERS-CoV and confirmed that the two cases in Springfield are MERS CoV or a closely allied strain. They agreed that they would collaborate on public statements concerning MERS, particularly important in light of the many misleading, alarming and misinformed reports in today's media concerning Ebola and Enterovirus-68.

On Friday morning, October 24, you will conduct a formal oral briefing of the Governor's top executives and staff (the Commissioner of the Department of Public Health, the Director of the Massachusetts Emergency Management Agency, and the Governor's director of communications and political advisor) on your assessment and recommendations for state action. The chief of staff asks that you highlight any specific actions involving the Governor, and that with all recommendations, you should be as specific as possible about timing, sequence, and future contingencies. 
Between now and the day of the briefing, SEF participants will receive periodic news briefs and announcements from public health agencies about events in the developing epidemic. This material and other information that discussion group members may gather should be incorporated in your group's work on this assignment.

On Friday, the $24^{\text {th }}$, each SEF discussion group will conduct its briefing before a panel of Harvard faculty and actual senior state officials from the relevant departments. Review panel members will rate and critique each discussion group's briefing individually following each presentation. They will also provide substantive comments on the potential epidemic and their overall impressions of the simulated briefings in full SEF sessions in the late morning and after lunch. 
Best Self in Teams 51

\section{APPENDIX B}

\section{Task Instructions and Checklists for Virtual Participants}

\section{(a) Task Instructions}

Big Restaurant is a nationwide restaurant chain that specializes in traditional American food such as burgers, steaks, and pastas. Known for their family-friendly and casual atmosphere, they have over 500 locations across the country. Because of recent successes, they are looking to expand by opening new restaurants.

Your group will play the role of purchasing executives for Big Restaurant who are tasked with evaluating three locations that are being considered for a new restaurant opening; East Point Mall, Starlight Valley, and Cape James Beach. Your group's job is to rank these locations in order from most to least desirable.

Big Restaurant wants your group to specifically focus on ten attributes, which they feel are most important in deciding the location to open a new restaurant. These attributes are: (1) at least 50 parking spaces, (2) larger than 2,000 square feet, (3) purchasing cost of less than \$1MM, (4) no more than 2 direct competitors in vicinity, (5) substantial foot traffic, (6) low maintenance costs, (7) large tourist population, (8) large student population, (9) quick access to waste disposal, (10) large population of employable individuals.

Please note that no attribute is more important than another, and all attributes should be treated equally. The most desirable location is the one that fulfills the largest total number of attributes (criteria).

Each member of the group has been provided with a list of attributes (criteria) that are satisfied by each location. Please note that each group member's list is different. Your list may not be complete (i.e. include blanks), and another group member may have information missing from your list. There are no inconsistencies or contradictions between lists. You may tell others information from your list, but please do not directly copy and paste, share, or display your list to other group members during the chat.

As mentioned above, your group's goal is to rank the three locations in order of most attributes met (i.e. the highest ranked location will meet the most criteria, second-highest location will meet the second-most criteria, etc.). You will have 15 minutes to complete the task. Good luck! 


\section{(b) Participant Checklists}

For all subjects: Please note, a "Yes" means the location meets that criterion. A "No" means the location does not meet that criterion. A blank means that this information has not been provided.

Participant 1

\begin{tabular}{|l|c|c|c|}
\hline Criterion & $\underline{\text { East Point }}$ & $\underline{\text { Starlight }}$ & $\underline{\text { Cape James }}$ \\
\hline At least 50 parking spaces & Yes & Yes & No \\
\hline Larger than 2,000 square feet & No & & \\
\hline Purchasing cost of less than \$1MM & & & \\
\hline No more than 2 direct competitors in vicinity & & & Yes \\
\hline Substantial foot traffic & Yes & & \\
\hline Low maintenance costs & & Yes & \\
\hline Large tourist population & No & & Yes \\
\hline Large student population & Yes & No & No \\
\hline Quick access to waste disposal & Yes & Yes & No \\
\hline Large population of employable individuals & Yes & No & Yes \\
\hline
\end{tabular}

Participant 2

\begin{tabular}{|l|c|c|c|}
\hline Criterion & $\underline{\text { East Point }}$ & $\underline{\text { Starlight }}$ & $\underline{\underline{\text { Cape James }}}$ \\
\hline At least 50 parking spaces & Yes & & No \\
\hline Larger than 2,000 square feet & & Yes & \\
\hline Purchasing cost of less than \$1MM & No & & Yes \\
\hline No more than 2 direct competitors in vicinity & & & Yes \\
\hline Substantial foot traffic & Yes & Yes & Yes \\
\hline Low maintenance costs & & & Yes \\
\hline Large tourist population & No & Yes & \\
\hline Large student population & Yes & No & \\
\hline Quick access to waste disposal & Yes & & \\
\hline Large population of employable individuals & Yes & No & \\
\hline
\end{tabular}

Participant 3

\begin{tabular}{|c|c|c|c|}
\hline Criterion & $\frac{\text { East Point }}{\text { Mall }}$ & $\frac{\text { Starlight }}{\text { Valley }}$ & $\frac{\text { Cape James }}{\text { Beach }}$ \\
\hline At least 50 parking spaces & $\overline{\text { Yes }}$ & & \\
\hline Larger than 2,000 square feet & & & No \\
\hline
\end{tabular}


Best Self in Teams 53

\begin{tabular}{|l|c|c|c|}
\hline Purchasing cost of less than \$1MM & & Yes & \\
\hline No more than 2 direct competitors in vicinity & No & Yes & \\
\hline Substantial foot traffic & Yes & & Yes \\
\hline Low maintenance costs & No & & Yes \\
\hline Large tourist population & No & & Yes \\
\hline Large student population & Yes & No & \\
\hline Quick access to waste disposal & Yes & & No \\
\hline Large population of employable individuals & Yes & No & Yes \\
\hline
\end{tabular}

